\title{
SOBRE OS LUGARES DA FILOSOFIA
}

\author{
Ronai Pires da Rocha' \\ Esse esforço que farei agora por deixar subir à tona um sentido, qualquer que seja, esse esfor- \\ ço seria facilitado se eu fingisse escrever para alguém.
}

Clarice Lispector, A Paixão Segundo G. H.

\section{INTRODUÇÃO}

Nos dias 4 e 5 de novembro de 2019 realizou-se, na Universidade Federal de Santa Maria, um "Encontro Regional da Residência Pedagógica em Filosofia", sobre o tema dos "lugares da Filosofia". A primeira parte da minha fala no evento foi dedicada à discussão de aspectos particulares do currículo local, em especial a questão dos critérios de decisão que levamos em conta nas reformas curriculares. Fiz uma breve revisão da história do Curso de Licenciatura em Filosofia da UFSM, que tem mais de cinquenta anos de funcionamento. Fiz também uma avaliação da conjuntura que vivemos no ensino de filosofia. Retomei 0 tema das dificuldades de caracterização da filosofia para sua apresentação didática e pedagógica. Na medida em que as decisões sobre o desenho curricular em nossa área são bastante amparadas nas intuições e preferências docentes, amplia-se a possibilidade de que elas sejam vistas como de ordem subjetiva. Eu tenho procurado identificar algumas dificuldades do que chamo de "decisionismo curricular", mas também tenho feito sugestões no sentido de que a exploração conceitual das diferenças entre três eixos no ensino da filosofia, como produto, como problema e como processo, pode ser o ponto de partida para novos esforços de caracterização da disciplina, a partir de seu eixo de procedimentos. O problema torna-se ainda mais premente no quadro político e social que estamos vivendo. Somam-se às dificuldades institucionais a necessidade de darmos conta de uma caracterização da filosofia que faça justiça não apenas a temas emergentes, mas ao processo de redesenho de suas próprias fronteiras. Nesta versão eu suprimi a abordagem da situação curricular da UFSM em benefício de uma expansão da segunda parte. Incluí algumas discussões que não apresentei naquele dia, em especial uma apresentação sobre A paixão segundo $G$. $H$., de Clarice Lispector, que me serviu, no presente texto, para fazer uma ponte entre certos temas. Incluí também uma abordagem de A Vida do Espírito, de Hannah Arendt, que me pareceu essencial para o mosaico que tento desenhar, faz anos. O resultado está longe de ser satisfatório. O fracasso, como diz Clarice, dá muito trabalho, pois para cair é preciso subir um pouco e "é inútil procurar encurtar caminho, a trajetória não é apenas um modo de ir, a trajetória somos nós mesmos".

\section{O CUSTO DAS ESCOLHAS}

Em Ensino de Filosofia e Currículo, apresentei uma "noção deflacionária da consciência crítica", cujo ponto central é a lembrança de uma relação, simultaneamente essencial e trivial, entre "conhecimento" e

1 Professor Aposentado do Departamento de Filosofia da Universidade Federal de Santa Maria. E-mail: ronairocha@gmail.com 
"criticidade". (Rocha, 2008, Cap. 2) O que me levou a isso foi a suspeita que o principal argumento que costumávamos apresentar em favor da presença da filosofia no currículo escolar, que a filosofia promove a formação da consciência crítica, estava esgotado. Eu escrevi, na ocasião, que nosso argumento estava esvaziado pela repetição e pelo fato que as demais disciplinas escolares consideravam-se, com justeza, igualmente essenciais para a formação de uma "consciência crítica". Fazíamos, na época, muita questão desse conceito, mas isso transformou-se aos poucos em um lugar comum, que exigia um trabalho de explicitação das diferenças específicas das disciplinas escolares. Havia muito o que fazer para que a presença curricular da filosofia fosse além do que constava nos principais manuais, fortemente datados, que então circulavam. Mais do que isso, tínhamos uma concepção de ensino de filosofia excessivamente centrada na vontade docente. A melhor mostra disso estava nos Parâmetros Curriculares Nacionais - Ensino Médio, nas orientações de Filosofia. ${ }^{2}$ Lá estava dito que a docência de Filosofia do Ensino Médio poderia decorrer da "opção por um modo determinado de filosofar" considerado justificado pelo professor. Éramos incentivados a fazer a nossa "escolha categorial e axiológica", a "escolha filosófica" que iria pautar nossas aulas.

A atuação docente a partir de escolhas conceituais por vezes altamente idiossincráticas, realizadas precocemente no espaço da formação docente, e de forma distanciada da dinâmica curricular escolar, pode levar a situações desastrosas, tanto do ponto de vista psicológico quanto do ponto de vista da teoria do currículo. Do ponto de vista psicológico, o professor corre o risco de abuso de seu poder curricular e pedagógico, pois nosso trabalho escolar precisa ser sustentado por uma rede intersubjetiva que proporcione um ambiente de supervisão. As decisões curriculares, pela sua condição pública, pedem uma sustentação intersubjetiva. Essas possibilidades de abuso ficam agravadas se e quando o professor de filosofia se compromete com conceitos de baixa complexidade, típicos dos confrontos políticos e culturais orientados pelo mercado imediatista da disputa política.

As escolhas didáticas para a aula de filosofia, quando ficam restritas ao universo de preferências pessoais do professor - aos temas e autores que ele escolheu para suas leituras de formação e trabaIhos acadêmicos - enviesam de forma arriscada o ambiente escolar. O mesmo acontece com qualquer outro desequilíbrio: atender apenas os pretensos desejos dos estudantes, atender apenas um programa para seleção universitária. Parece apenas evidente que nossos autores e textos favoritos, que as nossas convicções filosóficas, são apenas um dos tantos elementos que precisam ser levados em conta quando entramos na sala de aula. Na maior parte das vezes, eles devem contar apenas como o nosso horizonte pessoal de formação e referências, e não como sendo o currículo escolar. Não entramos na sala de aula para falar sobre nossos prazeres e sofrimentos conceituais. Ali precisamos respeitar as psicologias e as lógicas da aprendizagem e da formação humana, e isso não se confunde com a nossa paixão por esse ou aquele Platão. Não devemos ver como glória e conquista aquilo que é um rebaixamento de nosso compromisso pedagógico.

Vinte anos depois dos primeiros parâmetros, fica evidente a natureza conjuntural das orientações filosóficas que constam nos documentos da época, na medida em elas que estavam claramente centradas na preocupação com o direito do professor em considerar-se o centro e a fonte do processo educativo,

2 Parâmetros Curriculares Nacionais é um documento orientador da área, publicado em 2000, quando não havia obrigatoriedade nacional de ensino de Filosofia no currículo. 
em detrimento de uma discussão sobre formas cooperativas de entendimento sobre os demais aspectos envolvidos, em especial: a) o currículo escolar como algo que deve ser mais do que um agregado de escoIhas individuais, $b$ ) os direitos e expectativas de aprendizagem dos estudantes e, c) os conteúdos, atividades e habilidades relevantes na área de filosofia, para além das escolhas idiossincráticas de cada um de nós. E nisso ainda estamos, em uma crise ainda maior. Seguimos em um processo de sangria da expressão "consciência crítica" e continuamos usando manuais que praticamente não mudaram, que evidenciam uma fraca consciência curricular e interdisciplinar. Precisamos fazer mais para pensar sobre o que fazemos, sobre esse lugar para onde vamos, quando fazemos filosofia, seja em nossos escritórios, seja nas salas de aula. Mais uma vez vou falar em favor de uma concepção minimalista da filosofia.

\section{PARA ONDE VAMOS, QUANDO NOS DISTANCIAMOS DE NÓS MESMOS?}

"Onde estamos quando pensamos?" Essa pergunta é o título do quarto capítulo de A Vida do Espírito, de Hannah Arendt. O problema colocado por ela é familiar para a comunidade de debates sobre ensino de filosofia. Faz parte da tradição de nossos manuais de ensino de filosofia para o nível médio apresentar nossa disciplina, em primeiro lugar, como uma atitude de

não aceitar como óbvias e evidentes as coisas, as ideias, os fatos, as situações, os valores, os comportamentos de nossa existência cotidiana, jamais aceitá-los sem antes havê-los investigado e compreendido. ${ }^{3}$

Para realizar esse movimento de recusa, o mesmo manual sugere um procedimento que é conhecido entre nós como "ascensão semântica", e consiste, por exemplo, em passar de uma pergunta ou afirmação sobre fatos para uma pergunta ou afirmação sobre conceitos. Assim, passamos de "que horas são?" para "o que é o tempo?", de "eu te amo" para "o que é o amor" etc. O procedimento, é sugerido, aplica-se a todos os conceitos fundamentais da experiência humana. A fórmula é essa: a filosofia é um processo de "tomar distância de si mesmo e da vida cotidiana", um "interrogar a si mesmo". Nessa caracterização bem conhecida está contida a questão colocada por Hannah Arendt: onde estamos, quando pensamos? Qual a natureza desse lugar para onde vamos quando nos distanciamos de nós mesmos?

\section{A VELHICE E A HORA DE FALAR CONCRETAMENTE}

Deleuze \& Guattari começam a bem conhecida investigação, O que é a Filosofia? ${ }^{4}$ dizendo que essa questão é uma pergunta da velhice:

Talvez só possamos colocar a questão O que é a Filosofia? tardiamente, quando chega a velhice, e a hora de falar concretamente. ${ }^{5}$

3 Chauí, 2003, p. 36.

4 Deleuze \& Guattari, 1992, p. 9

5 Deleuze \& Guattari, 1992, p. 9. 
Há boas desculpas para isso. A bibliografia é muito magra, eles dizem, e a questão já foi colocada ao longo dos séculos, sempre de forma indireta, oblíqua, artificial, abstrata. Os filósofos não se ocuparam o bastante, nem com ela, nem "com a natureza do conceito como realidade filosófica."6 Assim, não é de estranhar que, na terceira idade, os dois filósofos se perguntem, o que foi isso que fiz toda a minha vida:

Tínhamos muita vontade de fazer filosofia, não nos perguntávamos o que ela era, salvo por exercício de estilo; não tínhamos atingido este ponto de não-estilo em que se pode dizer enfim: mas o que é isso que fiz toda a minha vida?

A comunidade ligada ao ensino de filosofia no Brasil conhece o prestígio da solução oferecida por eles: a filosofia não é contemplação, reflexão, conversação, aprender a pensar, espantar-se, conhecer-se a si mesmo. Contra essas alternativas, a solução deles é bem conhecida: "a filosofia é a arte de formar, de inventar, de fabricar conceitos", "a filosofia, mais rigorosamente, é a disciplina que consiste em criar conceitos." "Criar conceitos sempre novos, é o objeto da filosofia." ${ }^{8}$ Essa sugestão de identidade para a filosofia como criadora de conceitos, no final das contas e, na velhice, é mais uma dentre dezenas de propostas de apresentação da filosofia, muitas delas merecedoras de debates, muitas delas reveladoras de alguma faceta de nossa área de trabalho. Essa, em particular, não se afasta nem um pouco da tradição que diz que os filósofos fazem uma espécie de trabalho de inspeção de conceitos, e, nesse tanto, chegam mesmo a propor mais alguns.

O que me interessa na abordagem de Deleuze \& Guattari são outras coisas. A primeira delas é que eles têm razão quando dizem que a pergunta pela natureza da filosofia é muito diversamente respondida ao longo dos séculos, mas isso nunca impediu alguém de "fazer filosofia". Vamos admitir isso como um fato. Não seria interessante que, diante dele, a gente se perguntasse: como assim? Como funciona essa dinâmica, na qual dedicamo-nos a fazer uma coisa que não sabemos muito bem o que é? Não seria o caso de, em vez de propormos mais uma caracterização para a identidade da filosofia - como criação de conceitos, por exemplo -, examinássemos melhor a fluidez e a vagueza que parece fazer parte da própria essência da Filosofia? O que nomeamos, afinal, com esse nome? De resumo em resumo chegaremos a dizer que "filosofia" indica uma lista de discussões intermináveis sobre problemas fundamentais, eles mesmos sempre os mesmos e sempre outros, e que essa lista fica registrada nos escritos sobre esses problemas?

Quando optamos por descrições gerais desse tipo, estamos apenas adiando o problema do lugar da filosofia, por meio de um aplainamento de distinções agudas, como já lembrou Hannah Arendt. ${ }^{9}$ Aplainamos, em primeiro lugar, as diferentes formas de apresentação literária da filosofia, as roupas de sua apresentação, que vão do diálogo platônico ao comedido paper acadêmico. Em segundo lugar, aplainamos a intensidade de sua presença, sua intermitência, a diferença entre os vales onde ela por vezes hiberna e os picos onde ocasionalmente brilha. Pois não dizemos que ela, por vezes, vive épocas de sono

6 Deleuze \& Guattari, 1992, p. 20.

7 Deleuze \& Guattari, 1992, p. 9

8 Deleuze \& Guattari, 1992, Introdução.

9 Hannah Arendt, em A Vida do Espírito, nomeou como "aplainamento" a estratégia de apagar diferenças relevantes, como aquelas entre as mentalidades de gregos e romanos. Corre por minha conta dizer que essa é uma falha constante em nossos manuais de filosofia, ao ponto de fazer parecer que "todo mundo disse vagamente a mesma coisa". 
dogmático e outras de iluminação? Aplainamos, finalmente, a própria humanidade, pois não faz muito a filosofia era descrita como o triunfo da razão contra a mitologia. Nesse último aplainamento, porções inteiras da humanidade ficam de fora do espírito crítico, condenados a algum tipo de consciência ingênua, tradicional, vegetativa. ${ }^{10}$

\section{“O QUE É ISSO QUE FIZ TODA A MINHA VIDA?”}

O segundo aspecto interessante da abordagem de Deleuze \& Guattari é a questão da hora da filosofia. Como lembrei acima, eles dizem que o momento da investigação sobre a natureza da filosofia é a nossa chegada à velhice, esse "ponto de não estilo", essa despedida das aparências, portanto. É impossível aqui não lembrar de outras formulações semelhantes a essa, que parece dividir a obra dos filósofos em duas etapas que contrariam a Tese 11: os filósofos primeiro agem; depois, na terceira idade, eles interpretam.

Mencionarei apenas aquela que me parece a mais importante. Hegel, no prefácio à Filosofia do Direito, foi quem consagrou o tema: o pássaro de Minerva somente levanta voo quando as sombras da noite começam a cair. A filosofia, ensina Hegel, não tem, nem pode ter, a pretensão de ensinar como deve ser o mundo. Ela sempre chega tarde para isso, pois seu trabalho é o do reconhecimento das formas do mundo. A hora da filosofia, assim, é o crepúsculo dos dias e das épocas."1

Não faz falta prolongar o argumento sobre a hora tardia da filosofia. Não há um único manual de filosofia que não repita a história: a hora da filosofia chegou depois da mitologia. E quando os manuais são pressionados a responder pelas causas, razões ou motivos do surgimento da filosofia, da boca da razão por vezes sai um "milagre grego". Isso que fazemos em toda a nossa vida tem sua origem tisnada por paradoxos. Há, sim, um tempo para o surgimento da filosofia, mas essas horas são confundidas, nos manuais, com a voz e a escrita de algumas pessoas exemplares, como Tales, Heráclito, Parmênides, Sócrates, Platão, Aristóteles, que começam uma discussão interminável sobre problemas, dilemas, paradoxos fundamentais, mas também sobre tudo aquilo que, em nossa imaginação, tenha uma dimensão sobre a qual possamos refletir. Isto quer dizer, então, tudo. As metáforas para a hora crepuscular da filosofia, veremos logo adiante, bem que poderiam ser tomadas, por assim dizer, ao pé delas mesmas, pois é sempre sobre uma certa pré-existência que fazemos incidir nossas capacidades reflexivas. O objetivo da filosofia é muito tudo e vasto, como já disse, de forma bem humorada, Wilfrid Sellars:

O objetivo da filosofia, formulado abstratamente, é compreender como as coisas, no sentido mais amplo do termo, se relacionam no sentido mais amplo sentido possível do termo. Sob "coisas

10 Fernando de Azevedo, ao descrever o Brasil, em um texto de 1954, "Para a análise e interpretação do Brasil", disse haver aqui ainda a presença de coletividades isoladas, estáticas, "delimitadas e ainda dobradas sobre si mesmas". (Azevedo, 1958). A passagem foi reproduzida por Paulo Freire, que acrescentou que o homem brasileiro, nessas coletividades, se caracteriza por uma forte centralização de seus interesses "em torno de formas mais vegetativas de vida". (Freire, 2012, p. 32)

11 Hegel, 1976, p. 16. Marx não fez objeções a essa descrição da filosofia. Apenas radicalizou-a, ao dizer, repetidas vezes, que não há autonomia da filosofia. Para indicar ao menos uma das versões: "As fraseologias sobre a consciência acabam e o saber real tem de tomar o seu lugar. A filosofia autônoma perde, com a exposição da realidade, seu meio de existência". Marx, 2007, p. 95. 
Thaumazein, Ano IX, v. 13, n. 25, Santa Maria, p. 1-22, 2020.

no sentido mais amplo" eu incluo itens tão radicalmente diferentes como "repolhos e reis", mas também números e deveres, possibilidades e estalar de dedos, experiência estética e morte. Obter sucesso na filosofia seria, para usar um dito contemporâneo, saber a quantas a gente anda com respeito a todas essas coisas, não naquela forma não reflexiva na qual a centopeia da história sabia o que fazer antes de encarar a pergunta "como eu caminho?", mas na forma refletida que significa que nenhuma fortaleza intelectual está livre de ataque..2

Como devemos proceder, quando consideramos a presença curricular da filosofia no ensino? Diante dessas considerações, devemos ter presente o desafio de fazer justiça às justas demandas de reconhecimento da variedade das tradições e problemas reflexivos. Ela não pode e não deve ficar restrita à tradição cultural exclusiva daquela humanidade que se vê em continuidade aos gregos, romanos e cristãos, para que não fique de fora do âmbito dela a maior parte da humanidade. Se, como diz Sellars, a filosofia diz respeito às coisas no sentido mais amplo do termo, precisamos redescobri-la em formas ainda não suficientemente valorizadas por nós. Precisamos retomar a reflexão e aprofundá-la: o que é mesmo isso que fazemos como professores de filosofia no ensino fundamental e superior?

\section{VER O MUNDO DE MODO NENHUM?}

Arthur Danto fez uma sugestão perturbadora ao apresentar a variedade das formas de apresentação da filosofia. Ele disse que deveríamos adiar os debates sobre a natureza da filosofia até que ficassem mais claras as razões dessa "extraordinária profusão grafomórfica":

A questão mais profunda de saber o que é a filosofia talvez devesse ser adiada até que estivesse claro por quê essa extraordinária profusão grafomórfica é necessária. ${ }^{13}$

Quando comparamos a filosofia com as demais áreas das humanidades, sob esse aspecto da variedade de suas formas de apresentação, o tema torna-se ainda mais relevante, pois é evidente a assimetria dela em relação às demais áreas do pensamento e do conhecimento humanos. A filosofia apresenta-se, é certo, com as vestes da literatura, mas não encontramos isso na sociologia, na psicologia, na história.

Eu não tenho uma resposta para essa questão de Danto, e tampouco parece razoável suspender as conversas sobre o que é a filosofia até que as razões de seus disfarces e metamorfoses sejam melhor compreendidas. Quero arriscar aqui, no entanto, mais um passo em um programa de estudos nessa direção. Quero fazer isso de duas formas: relembrando a estrutura dos diálogos platônicos, nos quais há uma prática de ascensão semântica, e refletindo sobre algumas características das línguas naturais,

12 Sellars, 1991, p. 1. O itálico é meu. Uma parte essencial da caracterização feita por Sellars está na expressão "saber a quantas a gente anda." A frase parece ser uma homenagem a Wittgenstein, que escreveu, nas Investigações Filosóficas, \$123: "A philosophical problem has the form: "I don't know my way about", que eu traduzo assim: "Um problema filosófico tem a forma: "Eu não sei a quantas ando". A formulação de Wittgenstein é inspiradora, pois expõe claramente a principal razão que nos leva a filosofar, a saber, quando a gente está meio perdido.

13 Danto, 1982, p. 7. Ele volta ao tema em outros lugares, como em "Filosofia como/e/da literatura", em O Descredenciamento Filosófico da Arte. 
que nem sempre temos presente. É com essa estratégia que lidarei com essa pergunta: aplainadas as suas formas de expressão, o que é a filosofia?

Precisamos refazer o trabalho de identificação dos traços característicos daquilo que chamamos de tradição greco-ocidental da filosofia, para então reconhecer as linhas de identidade e diferença em relação a outras tradições culturais. Surgem aqui alguns obstáculos. O que há em comum, do ponto de vista filosófico, entre a tradição greco-ocidental cristã e todas as demais tradições de pensamento? Pode surgir aqui a tentação de dizer que cada cultura, cada tradição de pensamento é uma realização do espírito em pleno direito. O assunto ficaria assim resolvido em uma espécie de relativismo das tradições intelectuais. Essa solução evita a dificuldade de oferecer uma descrição mais precisa daquilo que há de comum entre as várias tradições reflexivas, para além de um rótulo vazio: todos os povos refletem sobre os problemas fundamentais da vida e da morte. "Todos os seres humanos são filósofos quando consideramos a filosofia como um modo de ver o mundo", alguém diria. O problema dessa fórmula é que, de uma ou de outra forma, vemos o mundo de algum modo e não é possível ver ou estar no mundo de modo nenhum. Esse tipo de grau zero da reflexão não oferece uma solução para a pergunta sobre uma identidade básica da filosofia para além ou aquém da tradição greco-romana-ocidental. ${ }^{14}$

\section{PENSAMENTOS DE SEGUNDA ORDEM}

A solução oferecida, desde séculos, para caracterizar o trabalho da filosofia, é bem conhecida. Ela está na estrutura dos diálogos socráticos. Pense em um diálogo como o Eutífron, por exemplo, no qual o personagem diz a Sócrates que vai processar o pai por impiedade. Ao invés de apoiar ou condenar a decisão, Sócrates desvia a conversa sobre, afinal de contas, o que é a piedade. Se você acha esse exemplo muito artificial, pense em um caso mais trivial, como o de um casal em crise porque uma pessoa pede à outra algum sacrifício que, no juízo do outro, vai além da conta. Ali pode surgir o espaço no qual um deles começa a pensar de novo sobre o que é, afinal de contas, "amar". Nesse caso, do nível "João ama Joaquim", uma descrição em primeira ordem, passamos para o debate infindável sobre "amar é .... Trata-se, portanto, da distinção entre pensamentos de primeira e segunda ordem, que já antecipei.

A comunidade brasileira de ensino de filosofia é familiarizada com essa distinção, pois ela consta dos manuais mais usados entre nós. Essa distinção pode ser nomeada de muitas formas. A diferença entre pensar sobre coisas, e pensar sobre pensamentos (ou linguagem), é também conhecida como "metacognição", "metalinguagem", "atitude teórica", e mesmo "pensamento científico" etc. Em todos eles, parte-se da diferença entre pensar sobre fatos, coisas, processos, eventos, e pensar sobre o pensar. No caso da filosofia costumamos acrescentar, como faz Marilena Chauí, que se trata de uma atividade de pensar sobre o pensar sobre tópicos fundamentais: tempo, sonho, verdade, ilusão, amor, igualdade, vontade, enfim, sobre os conceitos fundamentais da experiência humana.

Há vários componentes nessa descrição. O primeiro deles é o conceito de atividade, que indica que a filosofia deve ser vista como uma situação peculiar de agência; a filosofia é algo que fazemos em

14 Para uma caracterização do preconceito dos filósofos em relação ao pensamento oriental e, ao mesmo tempo, uma consideração das razões pelas quais deveríamos abandonar essa atitude, recomendo a segunda seção de "Em toda a parte e nenhuma", em Sinais, de Merleau-Ponty. 
primeira pessoa. O outro componente é o conceito de "segunda ordem". O juízo de primeira ordem é aquele que fazemos sobre sonhos e desejos, pão e vinho, pessoas e esperanças, fatos, coisas, eventos, processos, abóboras, carruagens e demais coisas do mundo. São, por isso mesmo, "juízos sobre o mundo". Já os juízos de segunda ordem tematizam a própria linguagem. Não é raro que esses conceitos sejam vistos como importante apenas para as aulas de lógica ou de linguística. O que quero enfatizar aqui é que ela opera no cotidiano linguístico.

Com essa argumentação quero borrar, ao menos um pouco, a linha de separação que costumamos traçar entre as consciências "críticas" e "ingênuas", reflexivas e cotidianas e, por assim dizer, entre uma razão triunfante e as mitologias deixadas para trás. É certo que nossos manuais de ensino de filosofia nunca deixam de acrescentar que a filosofia é um pensar com certos cuidados metodológicos. Esse acréscimo é feito porque parece evidente que as atitudes reflexivas, metacognitivas, não são e nunca foram privilégio de filósofos. Contrariamente a essa ideia impõe-se hoje outra: as capacidades reflexivas do sapiens são variadas, matizadas, complexas, e são parte do equipamento cognitivo das criaturas dotadas de linguagem proposicional, conceitual.

Quando alguém fala de vantagens da filosofia sobre a mitologia não quer dizer, por exemplo, que as mitologias não tratam de temas fundamentais da humanidade, não quer dizer que a mente selvagem não dá conta de si mesma e de seus problemas. A explicação repetida nos manuais é que se trata apenas de diferenças de atitudes metodológicas, pois a filosofia traz consigo um duplo distanciamento cognitivo: ela distancia seu agente do particularismo das tradições e do entorno cotidiano. Essa estratégia argumentativa preserva a possibilidade de pensamentos de segunda ordem nas mitologias e nas religiões. Afinal, em todas as mitologias e religiões há um trabalho de manutenção conceitual. Junto ao processo de elaboração e aprendizado dos cânones mitológicos e religiosos há também a necessidade de procedimentos de preservação e ajustamento aos novos desafios colocados pela realidade.

\section{ONDE HÁ LINGUAGEM, HÁ REFLEXÃO}

A afirmação que estou procurando articular aqui pode ser assim resumida: onde há linguagem proposicional (e isso quer dizer linguagem conceitual), há pensamentos de segunda ordem. Aqui eu estou considerando os traços comuns a que me referi acima, entre metacognição, metalinguagem e pensamentos de primeira e segunda ordem. Nesse momento estou me valendo de algo que tem sido observado por linguistas como Jakobson: "A faculdade de falar determinada língua implica a faculdade de falar acerca dessa língua". 15 Ele acrescenta mais adiante:

Uma distinção foi feita, na Lógica moderna, entre dois níveis de linguagem, a "linguagem objeto" que fala de objetos, e a "metalinguagem", que fala da linguagem. Mas a metalinguagem não é apenas um instrumento científico necessário, utilizado pelos lógicos e pelos linguistas; desempenha também papel importante em nossa linguagem cotidiana. ${ }^{16}$

15 Jakobson, 1977, p. 67

16 Jakobson, 1977, p. 127. Itálicos meus. 
Fazemos uso de metalinguagem, ele acrescenta, sempre que tropeçamos em palavras pouco conhecidas ou usadas de forma não convencional, quando não ficam claras as intenções do nosso interlocutor, quando não ouvimos bem, e assim por diante. Já nos usos cotidianos da linguagem, e não apenas no trabalho de tipo teórico, as práticas de primeira ordem incluem as práticas de segunda ordem. O ponto foi também exposto por Alva Noë:

Não existe essa coisa como o usuário da linguagem ingênuo, não-reflexivo, sem viés teórico. Isso é assim porque compreender uma palavra é saber como usá-la e isso significa, entre outras coisas, saber como explicar seu uso para outra pessoa, como responder a pergunta 'o que isto significa?'17

Nosso comportamento, como usuários de uma língua natural, inclui naturalmente o cuidado e o descuido com os usos dos conceitos. Estamos expostos a muitas situações nas quais exploramos e somos explorados por pequenas ou grandes variações de significado, por generalizações indevidas, vaguezas propositais, ambiguidades calculadas, metáforas pouco apropriadas, pequenas disfuncionalidades de comunicação com as quais aprendemos a conviver e a controlar, quando possível e adequado. Nosso domínio de um conceito, a partir de uma certa idade linguística, inclui não apenas a capacidade de aplicá-lo corretamente, mas também de perceber os usos diferentes do mesmo conceito. Essas capacidades são inerentes ao processo de aprendizagem da língua materna. No cotidiano, lembra Jakobson, por vezes não compreendemos o que alguém nos disse por uma questão de deficiência de nosso léxico. $\mathrm{E}$ eu acrescento: mas também porque nosso interlocutor faz um uso desleixado de algum conceito, porque estou ficando surdo, porque há muito ruído no ambiente, porque o outro falou mastigando, porque é uma implicação que me custa acreditar, porque ele disse algo que não quero acreditar, e assim preciso dizer a ele, "o que você quer dizer com isso?" ou perguntar-me, pensando no que eu disse e nas implicações do meu dito, "é isso mesmo que eu quero dizer?". Enfim, seja na dimensão dos significantes, seja no nível semântico, as operações metalinguísticas são de uso corrente.

\section{O GRAU ZERO DO CUIDADO DE SI}

Uma língua natural é um comportamento simbólico que traz consigo "dinâmicas cognitivas de segunda ordem". ${ }^{18}$ Isso decorre, dentre outras causas, da forma peculiar de funcionamento dos componentes essenciais da linguagem, dentre esses, os conceitos. Esses são, por assim dizer, dispositivos de classificação com propriedades inferenciais, e a nossa progressiva apropriação deles, no nível ontogenético, acarreta inevitavelmente uma espécie de grau zero do cuidado de si, que consiste no fato que o bebê não cuida de si, que a criança aprende a cuidar de si com quem cuida dela, que cada palavra e

17 Noë, 2012, p. 3.

18 Mariela Aguilera resume esse ponto. A expressão "dinâmica cognitiva de segunda ordem" indica a nossa capacidade de avaliação de raciocínios, dos nossos e dos outros. Somente uma língua natural - em contraposição com uma linguagem do pensamento - pode desempenhar este papel, já que as representações exploradas na leitura da mente - prática que parece exigir pensamentos de segunda ordem - devem ser conscientes ou de nível pessoal, para que se possam usar na tomada de decisões práticas do agente. Ver Aguilera, 2013, p. 65ss. 
cada gesto da criança são acompanhados de palavras e gestos de aprovação ou recusa. Jakobson afirma que "todo processo de aprendizagem da linguagem, particularmente a aquisição, pela criança, da língua materna, faz largo uso de tais operações metalinguísticas." ${ }^{\prime 19}$ E aos poucos ela aprende, como diz Lewis Carrol, que não podemos mandar ao bel prazer nas palavras, na imensa maioria delas.

"Justiça", por exemplo, é uma expressão comum, de uso cotidiano, que entra no vocabulário de uma criança muito cedo, e que frequentemente é objeto de polêmicas no cotidiano. No nível de primeira ordem, acusamos alguém de um comportamento injusto. No nível de segunda ordem, que surge quando temos dúvidas sobre se alguém foi justo em sua decisão, abre-se a conversa sobre o que é, afinal de contas, "ser justo". A fórmula é frequentemente repetida nos livros de introdução à filosofia: a filosofia é uma atividade na qual ocorre a suspensão de nossos juízos cotidianos para que possamos tematizar os conceitos mais gerais e fundamentais que os integram. O que estou sustentando aqui, para borrar certas linhas, é que essa "suspensão do cotidiano" é algo muito amplo, ocorre de muitas formas, e aquilo que chamamos de "filosofia" é uma parte dela, por vezes maior, por vezes, menor.

Pense no caso da criança que faz perguntas sobre sua própria história, sobre sua origem e nascimento. Ela aprende que veio da barriga da mãe e da semente do pai, que, por sua vez, veio da barriga da avó e da semente do avô e assim por diante. Ao perguntar pelo primeiro pai do mundo, falam para ela em Adão e Eva. A criança pode muito bem seguir perguntando sobre o pai de Adão e de Eva. O ensinamento que ela recebe para entender essa história é que as coisas têm causas: que o cocô ficou duro porque ela não come legumes, que ela pode ficar boa se tomar remédio, que, se ela ficar pelada, vai ficar gripada, e assim por diante, uma coisa pode ser vista como causa da outra e que é difícil saber o quê leva ao quê. Ela quer saber de onde veio Eva. Quando dizem que Eva veio de Deus, a criança vai parar? Afinal, Deus é um ser, e todo ser vem de outro ser. E de onde veio Deus? E assim pode ficar difícil para ela escrever deus em maiúscula, porque nos esquemas conceituais dela deus é como brócolis, algo que está em uma cadeia causal, submetido às regras das coisas e precisando de uma causa. Como fazemos para a criança pensar em algo que pode ser sua própria causa?

Quero sugerir com esse argumento que certos conceitos muito gerais (como o de causalidade, e tantos outros) têm um modo de funcionamento muito complexo e variado; quando, por alguma razão, eles são tematizados, temos várias alternativas: esquecer o problema, trocar de assunto, fazer de conta que não vimos, tamponá-lo. A filosofia, dizemos, é uma das tantas formas de encarar de frente problemas desses tipos, de situar-se melhor diante de certas dificuldades, desarranjos e desorganizações conceituais.

\section{UM EXEMPLO: A FILOSOFIA, SEGUNDO CLARICE LISPECTOR}

Onde termina a literatura e começa a filosofia? Onde termina a filosofia e começa a literatura? As linhas de separação nem sempre são claras, como no caso de certas fronteiras líquidas entre países: com chuvas, inundações e alagamentos, o rio tem suas margens alteradas, pode mesmo mudar seu curso, e será preciso negociar novos mapas.

Há filosofia na obra de Clarice? Entre nós, Benedito Nunes argumentou em favor de sua inserção no contexto da filosofia da existência. Segundo Nunes, a "concepção-do-mundo de Clarice Lispector tem 19 Jakobson, 1977, p. 127. 
marcantes afinidades com a filosofia da existência (...)". ${ }^{20} \mathrm{O}$ exemplo dado por ele é a presença do tema sartreano da náusea, que pode ser localizado em Laços de Família (na visita de Ana ao Jardim Botânico), em A Maçã no Escuro (Martim, no curral das vacas) e em A Paixão Segundo GH, "onde o desencadeante da náusea é uma barata que a personagem narradora vê, no quarto da empregada, saindo de dentro de um banal guarda-roupa."21 Hélène Cixous, na tradição de estudos literários franceses, sustentou que Clarice faz filosofia em seus textos; ela não cria conceitos, ela não cita autores, mas ela reflete sobre questões genuinamente filosóficas. Como assim? ${ }^{22}$

A paixão segundo $\mathrm{GH}$, de Clarice Lispector, é um texto que apresenta, na fala em primeira pessoa de sua personagem, algumas das características centrais da filosofia, em um sentido mais amplo do que aquele da concepção existencialista, sugerido por Nunes. ${ }^{23}$ Quero mostrar de que modo a obra pode ser vista como uma atividade de reflexão sobre conceitos muito gerais que estruturam a vida da personagem, e que isso preenche algumas características da filosofia. A personagem do romance encena um caso de grau zero da filosofia; sua "criticidade", por assim dizer, se faz presente a partir de uma situação de desorientação, de uma necessidade inadiável de reorganização conceitual.

O primeiro parágrafo de A Paixão Segundo GH descreve o sentimento da personagem de estar perdida, e, mais precisamente, de estar profundamente desorganizada.:

estou procurando, estou procurando. Estou tentando entender. Tentando dar a alguém o que vivi e não sei a quem, mas não quero ficar com o que vivi. Não sei o que fazer do que vivi, tenho medo dessa desorganização profunda. Não confio no que me aconteceu. Aconteceu-me alguma coisa que eu, pelo fato de não a saber como viver, vivi uma outra? A isso quereria chamar desorganização, e teria a segurança de me aventurar, porque saberia depois para onde voltar: para a organização anterior. A isso prefiro chamar desorganização, pois não quero me confirmar no que vivi - na confirmação de mim eu perderia o mundo como eu o tinha, e sei que não tenho capacidade para outro. ${ }^{24}$

As duas primeiras palavras da novela dão o tom. Ninguém procura sem ter perdido algo, sem estar perdido. A perda indicada por ela é profunda, de mundos, de compreensão, de entendimento. Essa falta gera uma profunda desorganização. Os itálicos na passagem são meus e visam destacar o fato que a palavra "organização" é repetida três vezes no parágrafo de abertura da novela, e é retomada nos parágrafos seguintes, ao menos dez vezes nas três primeiras páginas do romance. Todas as demais ocorrências dessa expressão estão ligadas ao tema que abre o livro: estar perdida, não saber como voltar, perder o mundo, viver algo sem saber vivê-lo. O tema é reapresentado mais diretamente na segunda página da novela:

20 Nunes, 1969, p. 93.

21 Nunes, 1969, 100.

22 Cixous, 1990.

23 O tema é polêmico. Moser (2009) escreve que “... as comparações de Clarice Lispector com Sartre são tão descabidas: 0 mundo da política, do 'novo homem', da revolução e da ideologia, é totalmente alheio a ela. Para alguém com a sua formação, tendo visto aonde a revolução e a ideologia levam, provavelmente não poderia ser de outra forma." (p. 227) 24 Lispector, 1986, p. 7. Itálicos meus. 
Thaumazein, Ano IX, v. 13, n. 25, Santa Maria, p. 1-22, 2020.

Ontem, no entanto, perdi durante horas e horas a minha montagem humana. Se tiver coragem, eu me deixarei continuar perdida. Mas tenho medo do que é novo e tenho medo de viver o que não entendo - quero sempre ter a garantia de pelo menos estar pensando que entendo, não sei me entregar à desorientação. (...) Por que é que ver é uma tal desorganização?25

O episódio em torno do qual o livro gira, o contato com a barata, tem um contexto que está em sintonia com esses usos de "organizar". Isso fica claro nas primeiras páginas:

Levantei-me enfim da mesa do café, essa mulher. Não ter naquele dia nenhuma empregada, iria me dar o tipo de atividade que eu queria: o de arrumar. Sempre gostei de arrumar. Suponho que esta seja a minha única vocação verdadeira. Ordenando as coisas, eu crio e entendo ao mesmo tempo. (...) Arrumar é achar a melhor forma. ${ }^{26}$

A atividade de arrumar a casa, por mais trivial que pareça, atende aos requisitos sugeridos por Alva Noë, para a distinção que abordei anteriormente, entre primeira e segunda ordem. Em Ferramentas Estranhas, ele retomou e ampliou esse tema, argumentando que as atividades triviais, como conversar, dançar, fazer desenhos, são modos básicos e involuntários de organização humana. Incluo aqui, por minha conta, a arrumação de casa. Ou seja, não temos alternativa a não ser fazer coisas muito básicas como essas. $\mathrm{O}$ modo de funcionamento dessas atividades leva a práticas de reorganização que retroa-

25 Nas páginas 8-9. Para deixar clara a importância desse conceito na novela vou indicar outras ocorrências dela: Na página 21: "Esse - apenas esse - foi o meu maior contato comigo mesma? O maior aprofundamento mudo a que cheguei, minha ligação mais cega e direta com o mundo. O resto - o resto eram sempre as organizações de mim mesma, agora sei, ah, agora eu sei." Na página 24: "Eu não me impunha um papel mas me organizara para ser compreendida por mim, não suportaria não me encontrar no catálogo." Na página 63: "Vê, meu amor, vê como por medo já estou organizando, vê como ainda não consigo mexer nesses elementos primários do laboratório sem logo querer organizar a esperança." Na página 90: "Mãe: matei uma vida, e não há braços que me recebam agora e na hora do nosso deserto, amém. Mãe, tudo agora tornou-se de ouro duro. Interrompi uma coisa organizada, mãe, e isso é pior que matar (...)". Na página 94: (90) "Para ter chegado a isso, eu abandonara a minha organização humana - para entrar nessa coisa monstruosa que é a minha neutralidade viva." Na página 95: "E não apenas viva - como estava apenas viva aquela barata primariamente monstruosa - mas organizadamente viva como uma pessoa. A identidade - a identidade que é a primeira inerência - era a isso que eu estava cedendo? Era nisso que eu havia entrado? A identidade me é proibida, eu sei. Mas vou me arriscar porque confio na minha covardia futura, e será a minha covardia essencial que me reorganizará de novo em pessoa. Não só através da minha covardia. Mas me reorganizarei através do ritual com que já nasci, assim como no neutro do sêmen está inerente o ritual da vida." Na página 142: "Eu nunca havia deixado minha alma livre, e havia me organizado depressa em pessoa porque é arriscado demais perder-se a forma." Ainda na página 142: "Sei que se eu abandonar o que foi uma vida toda organizada pela esperança, sei que abandonar tudo isso - em prol dessa coisa mais ampla que é estar vivo - abandonar tudo isso dói como separar-se de um filho ainda não nascido. A esperança é um filho ainda não nascido, só prometido, e isso machuca." Na página 155: "Não posso pôr em palavras qual era o sistema, mas eu vivia num sistema. Era como se eu me organizasse dentro do fato de ter dor de estômago porque, se eu não a tivesse mais, também perderia a maravilhosa esperança de me livrar um dia da dor de estômago (....)" O tema da organização está presente também no final do livro, na página 175: "Minha vida não tem sentido apenas humano, é muito maior - é tão maior que, em relação ao humano, não tem sentido. Da organização geral que era maior que eu, eu só havia até então percebido os fragmentos." Itálicos meus.

26 Lispector, 1986, p. 29. Itálicos meus.

periodicos.ufn.edu.br/index.php/thaumazein 
gem sobre o nível básico. Uma atividade básica, (de primeira ordem) como conversar com alguém sobre algum assunto do cotidiano está sempre ligada a tarefas cognitivas como ouvir, prestar atenção no outro, raciocinar, lembrar, argumentar, formar ou desfazer crenças, acumular conhecimentos. Uma pequena conversa sobre o pãozinho francês para o café da manhã de amanhã nos exige, inacreditavelmente, um certo esforço de organização e reorganização. Na arrumação da casa encontramos uma caixa de papelão com cartões postais de vinte anos atrás e, num passe, o dia fica suspenso em memórias perturbadoras.

Podemos agora voltar agora ao tema: uma atitude reflexiva sobre a linguagem parece fazer parte do modo de funcionamento da linguagem proposicional. Na perspectiva de Clarice Lispector, é como se a escrita fosse uma necessidade cotidiana de organização e reorganização humanas, que tem o condão de retroagir e realimentar a forma como vivemos. Escrever, para ela, era um ato de organização do pensamento e da vida. Escrever nos organiza, escrever nos reorganiza. Ela escrevia para se manter viva e orientada, como se fosse um animal extraviado. Certa feita lhe perguntaram por que ela escrevia. A resposta veio na forma de outra pergunta: "Por que você bebe água?"

Se a linguagem é como a água, como poderíamos ser e viver sem ela? Isso inclui também: como poderíamos ser indiferentes à qualidade e à disponibilidade dela, suas formas de posse, conservação e distribuição? De forma semelhante,

não poderia haver linguagem, na forma como a conhecemos, na ausência de atitudes, valores, normas, prescrições e ideologias sobre linguagem. Nunca houve um Jardim do Éden, e assim nunca houve uma língua que fosse levada adiante e usada de forma automática, livre, sem qualquer necessidade de reflexão sobre questões básicas como: De que modo seguir? O que é o certo e o errado? O que ele quis dizer quando disse aquilo? Porque ele disse aquilo? e assim por diante. ${ }^{27}$

\section{ESTRELAS POLARES}

Aqui eu não posso fazer mais do que seguir sugerindo um programa de trabalho e algumas metáforas orientadoras. Precisamos aterrar a discussão sobre a natureza da filosofia em um contexto bem definido: nossa presença no currículo do ensino médio e o que decorre disso. Como já adiantei, a boa razão para uma retomada da discussão sobre a natureza da filosofia é o esvaziamento dos slogans que usamos na defesa da disciplina, durante décadas, que a apresentavam como voltada para a formação de uma consciência crítica e reflexiva. Não podemos fazer vista grossa para o fato que todas as disciplinas escolares dizem a mesma coisa sobre elas mesmas. As atividades reflexivas se fazem presente não apenas em todas as disciplinas escolares, mas, muito claramente, no próprio modo de funcionamento da linguagem humana e, diante disso, especialmente para finalidades de desenho curricular, a filosofia pode e deve ser vista como uma das variedades do pensamento humano de tipo metacognitivo, de segunda ordem, teórico, metalinguístico. ${ }^{28}$

27 Noe, 2015, p. 34.

28 Antes de ser abandonado pelo leitor nesse ponto, convém fazer uma nota. Nos limites desse texto eu não vou apresentar (até porque esses temas ainda não estão suficientemente claros para mim) as respostas para essa objeção: "De mínimo em mínimo vamos chegar, daqui a pouco, a uma total indistinção entre um sentido forte de crítica (como o Kant) e o sentido de 
O quanto nos ocupamos com filosofia, em que épocas de nossas vidas e em quais circunstâncias nos ocupamos - no encontro com uma barata! -, de que modo nos ocupamos com atividades reflexivas sobre os aspectos mais gerais e fundamentais da vida é algo fortemente variável e, sob muitos aspectos, imprevisível na sua intensidade, duração, ocasião e forma. O contexto escolar é uma dessas circunstâncias especiais, onde podemos planejar essas variáveis e não apenas dar vazão ao nosso gosto por certos autores e temas. Não podemos perder de vista que a especificidade da filosofia, entre outros aspectos, diz respeito ao fato dela se ocupar com uma região de conceitos fundamentais da experiência humana, o que faz com que suas origens, limites e possibilidades sejam esfumadas, e que isso pode facilmente ser uma ocasião de extravio.

A natureza da região conceitual é uma questão que devemos considerar em aberto. Basta ver as dificuldades que temos para simplesmente conceituar "conceito". É verdade que fazemos coisas importantes com os usos que damos a essa palavra, mas é também verdadeiro que temos ainda muito o que fazer para responder perguntas como a de Hannah Arendt: o que é essa região dos conceitos fundamentais? Onde estamos, quando pensamos? O que são os conceitos? Se eles constituíssem um imenso oceano, como na metáfora de Kant, haveria nele alguma estrela polar?

A premissa que estou mantendo é que não é razoável pensar que podemos ter apenas pensamentos de primeira ordem. Mesmo quando falamos das dinâmicas cognitivas das "comunidades dobradas sobre si mesmo" nos vemos obrigados a atribuir a elas um tipo de consciência reflexiva que chamamos de ingênua, não crítica, mitológica, tradicional. Uma dimensão metacognitiva não é um acréscimo temporalmente tardio, feito sobre uma língua natural que começa funcionando apenas no nível de primeira ordem. Os pensamentos de segunda ordem fazem parte do modo de funcionamento de uma língua natural, por um conjunto muito amplo de razões, tanto da ordem de funcionamento dos significantes da linguagem quanto por razões pragmáticas e semânticas.

Uma questão que não pretendo discutir aqui, mas que deve fazer parte de um programa especulativo desse tipo, é aquela das formas de influência dos pensamentos de segunda ordem sobre os pensamentos de primeira ordem. Grosso modo, nossas teorias intuitivas sobre as consciências ingênuas e as mitologias resumem-se a afirmar que o efeito retroativo das metacognições é apenas o de realimentar as certezas de primeira ordem ou que há algum dispositivo de bloqueio para certos aspectos semânticos da metacognição. O que estou querendo dizer aqui é que não é possível bloquear a dimensão, por assim dizer, da infraestrutura da metacognição, pois ela opera, por exemplo, já na racionalidade instrumental. Eu não posso evitar o pensamento sobre as desvantagens que tenho ao usar um instrumento defeituoso ou em não ouvir claramente o que me dizem. No que diz respeito aos aspectos semânticos, acho que é uma bobagem pensar em uma coletividade onde ninguém duvida da deusa mandioca ou da deusa capivara.

crítica que podemos encontrar na filosofia tibetana, nos kadiweu e nas mitologias em geral. Nessa toada todo mundo terá direito a algum tipo de pensamento crítico e a filosofia se esfuma." Minha linha de argumentação consistirá em lembrar que as dinâmicas cognitivas que estou sugerindo aqui precisam ser inseridas em contextos históricos e sociais que serão decisivos para a aceleração, aprofundamento e direcionamento das cognições de segunda ordem. Elas sofrem, em circunstâncias as mais diversas, a ação de mecanismos de tipo psicopolítico (como racionalizações, dissonâncias cognitivas, manipulações, etc). O que eu pretendo aqui, no momento, é mostrar que o baratilho da distinção entre consciências críticas e ingênuas compra tantas coisas como o faz uma nota de sete reais. 
Essa comunidade certamente providenciará um remédio conceitual para aqueles que duvidam dessas divindades. A epistemologia que gerou o par de conceitos "consciência ingênua e crítica", era mais do que uma patente ingenuidade esquemática, pois ela permitia dizer que havia comunidades desprovidas daquelas metacognições que alguns intelectuais ou professores gostariam que elas tivessem.

Os pensamentos de segunda ordem, como estou sugerindo, podem ter diversas formas de influência sobre os pensamentos de primeira ordem. Pensar sobre meus pensamentos pode me levar a revisá-los, mas também a achar que estão em ordem. Posso revisá-los em parte, totalmente, provisoriamente, conjunturalmente. No dizer de Clark, as dinâmicas cognitivas de segunda ordem perfazem um

conjunto de capacidades poderosas que envolvem auto-avaliação, autocrítica e respostas corretivas refinadas. Os exemplos incluem: reconhecer uma falha em nosso próprio plano ou argumento e dedicar mais esforços cognitivos para corrigi-la; refletir sobre a falta de confiabilidade de nossos próprios julgamentos iniciais em certos tipos de situações e proceder com cautela especial como resultado; chegar a ver por que chegamos a uma conclusão específica, apreciando as transições lógicas em nosso próprio pensamento; pensar nas condições em que pensamos melhor e tentando promovê-las. A lista pode ser continuada, mas o padrão deve ser claro. ${ }^{29}$

Há uma progressão nos exemplos oferecidos por Clark. Os primeiros aplicam-se ao planejamento de caçadas, à construção de abrigos e a estratégias de batalhas; os últimos exemplos podem ser aplicados ao crescimento das ciências e dos processos elaborados de ensino. Há uma hierarquia nas dinâmicas cognitivas de segunda ordem, que começa no nível da racionalidade instrumental, com a avaliação da capacidade de ataque de pedras, lanças e martelos e prossegue até os níveis sofisticados da psicanálise e da autocrítica. O que parece faltar aqui é o reconhecimento de que esse conjunto de capacidades poderosas de revisão cognitiva pode também concluir que, como tudo está, está bem. ${ }^{30}$

\section{AVENTURAS DA METÁFORA}

No que segue, vou seguir uma sugestão de ver as metáforas e as analogias como um tipo peculiar de pensamento de segunda ordem, pois nelas nossa pretensão de falar sobre as coisas vem depois de uma transferência no interior da linguagem, como disse Aristóteles: a metáfora é o transporte do nome de uma coisa para outra coisa.

A reflexão sobre os benefícios e os riscos dos pensamentos de segunda ordem não é um privilégio dos departamentos de filosofia. Mães e pais, filhos e filhas, funcionários do comércio, cidadãos, todos podemos suspeitar de reflexões, metáforas e analogias mal feitas. No caso do patrão que quer tratar seus empregados como família, no caso do político que quer que o cidadão veja na pátria sua mãe, os perigos da analogia estão ao alcance dos letrados em geral. As dificuldades surgem a todo momento, pois se é verdade que há casos em que podemos ver facilmente os riscos de uma analogia, na maioria das vezes eles são mais sutis. ${ }^{31}$

29 Clark, 1998, p. 177.

30 veja a nota 27.

31 Wittgenstein sugere que "é impossível precisar com nitidez os casos em que poderíamos dizer que alguém foi induzido em erro por uma analogia." Wittgenstein, 1965, p. 3. 
Não vamos muito longe, no pensamento, sem o apoio das analogias, das metáforas, das comparações. Hannah Arendt sugeriu ainda mais do que isso. Ela afirmou que o uso de metáforas é uma condição da vida do espírito.

"Este assunto até agora foi pouco analisado, embora ele mereça uma investigação mais profunda."32 A frase é de Kant, na Crítica do Juízo, e era uma referência ao tema da metáfora, as "apresentações indiretas". O juízo de Kant sobre a importância e a falta de estudos sobre a metáfora foi considerado atual ainda nos anos 1970, quando Hannah Arendt discutiu o tema em A Vida do Espírito. Kant acrescentou, na mesma passagem, que a linguagem humana está repleta de metáforas, analogias, apresentações indiretas e homenageou Locke na mesma passagem da Crítica, ao lembrar que importantes conceitos da filosofia, como fundamento, depender, fluir, substância, são analogias, transferências, metáforas.

Hannah Arendt dedicou as seções 12 e 13 de A Vida do Espírito à metáfora, mas introduziu o tema bem antes, no mesmo livro. Ela começa a seção 4, "Corpo e alma; alma e espírito", com uma afirmação que guiará toda a investigação sobre o tema:

O emprego de metáforas caracteriza a nossa linguagem conceitual, própria para tornar manifesta a vida do espírito. As palavras que usamos em linguagem estritamente filosófica também são invariavelmente derivadas de expressões relacionadas com o mundo tal como ele é dado aos nossos cinco sentidos, de cuja experiência elas são, então, como registrou Locke, "transferidas" - metapherein, transportadas - "para significações mais abstrusas, passando a representar ideias que não chegam ao conhecimento de nossos sentidos". ${ }^{33}$

Destaco três aspectos nessa passagem. O primeiro é a posição pioneira que ela assume, no começo dos anos 1970, nos debates sobre epistemologia da metáfora, a saber, que a metáfora é parte essencial de nossa linguagem conceitual. Essa posição afrontava diretamente as posições filosóficas em voga, que viam na metáfora um dispositivo apenas de natureza retórica ou pragmática. A segunda afirmação forte é que a metáfora é o meio adequado para a manifestação da vida espiritual. Creio que até hoje esse ponto não é adequadamente apreciado. Em terceiro lugar, também contra as modas da época, ela foi capaz de conceder a Locke a originalidade da intuição sobre o tema: o transporte realizado pela metáfora cria uma espécie de ponte entre o mundo da sensibilidade e das aparências ao mundo do espírito. ${ }^{34}$

A teoria da metáfora que ela nos oferece no livro é bastante complexa, e não posso resumi-la aqui além de três aspectos. O primeiro deles, que adiantei acima, é essa dependência mútua entre pensamento e linguagem e, mais ainda, no que diz respeito aos temas da vida do espírito, entre pensamento, linguagem e metáfora, pois são elas que possibilitam o preenchimento da "lacuna entre um mundo dado à experiência sensorial e um domínio onde tais apreensões imediatas de evidência não podem existir." Ou seja, sem as metáforas, não há uma forma alternativa de manifestação da vida do espírito.

32 Kant, Crítica do Juízo, \$59.

33 Arendt, 1992, p. 25.

34 A epistemologia da metáfora firmou-se nos Estados Unidos exatamente na segunda metade dos anos 1970. Essa é outra longa e bela história, que não posso contar aqui por falta de espaço. 
Thaumazein, Ano IX, v. 13, n. 25, Santa Maria, p. 1-22, 2020.

A metáfora, servindo de ponte no abismo entre as atividades espirituais interiores e invisíveis e o mundo das aparências, foi certamente o maior dom que a linguagem poderia conceder ao pensamento e, consequentemente à filosofia; mas a metáfora em si é, na origem, poética, e não filosófica. ${ }^{35}$

Em segundo lugar ela introduz, sem desenvolver, um par de teses sobre a origem e a natureza da filosofia que estão em continuidade com as afirmações iniciais sobre a essencialidade do papel cognitivo da metáfora. Em primeiro lugar, ela sustenta que não é razoável imaginar o surgimento da filosofia "sem a recepção e a adaptação iniciais do alfabeto feitas pelos gregos a partir das fontes fenícias" ${ }^{36}$ Depois de sugerir essa tese externalista, ela escreve que "toda a linguagem filosófica, e a maior parte da linguagem poética, é metafórica", e, assim, linguagem, filosofia, e metáfora ficam ligadas.

\begin{abstract}
A linguagem, o único meio pelo qual é possível tornar manifestas as atividades espirituais não só para o mundo exterior como também para o próprio eu espiritual, não é de modo algum tão evidentemente adequada à atividade do pensamento quanto a visão o é para sua tarefa de ver. Nenhuma língua tem um vocabulário já pronto para as necessidades da atividade espiritual; todas tomam seu vocabulário de empréstimo às palavras originalmente concebidas para corresponder ou a experiências dos sentidos, ou a outras experiências da vida comum. Tal empréstimo, entretanto, jamais se dá ao acaso ou é arbitrariamente simbólico (como os símbolos matemáticos) ou emblemático. ${ }^{37}$
\end{abstract}

Os termos filosóficos, ela prossegue, são "metáforas, analogias congeladas" ${ }^{38}$ e essas, por sua vez, são os fios com os quais "o espírito se prende ao mundo". Se podemos falar, em algum sentido, sobre alguma "unidade da experiência humana', é graças às analogias e metáforas, que

servem como modelos no próprio processo de pensamento, dando-nos orientação quando tememos cambalear às cegas entre experiências nas quais nossos sentidos corporais, com sua relativa certeza de conhecimento, não nos podem guiar.

O terceiro aspecto que quero destacar surge aqui, e diz respeito ao papel essencial do pensamento metafórico, o de lançar pontes sobre o abismo que há entre o domínio espiritual e o mundo das aparências. O pensamento, com suas capacidades metafóricas, é uma atividade do espírito que torna manifesta os produtos do espírito que são dependentes da linguagem, pois

pensar é a atividade do espírito que dá realidade àqueles produtos do espírito inerentes ao discurso e para os quais a linguagem, sem qualquer esforço especial, já encontrou uma morada adequada, ainda que provisória, no mundo audível. ${ }^{39}$

35 Arendt, 1992, p. 81.

36 Arendt, 1992, p.79.

37 Arendt, 1992, p. 79.

38 Arendt, 1992, p. 80 . O leitor lembrará aqui uma passagem semelhante, em Nietzsche. A pandemia que estamos vivendo, em 2020, me separou desse e de outros livros meus.

39 Arendt, 1992, p. 84. 
Thaumazein, Ano IX, v. 13, n. 25, Santa Maria, p. 1-22, 2020.

Ficam unidas assim as teses sobre a filosofia, que começam com a importância da escrita alfabética grega e chegam ao reconhecimento das formas de pensamento filosófico do "mundo audível".

A teoria dos dois mundos, como já disse, é uma falácia metafísica, mas não é absolutamente arbitrária ou acidental. É a falácia mais razoável que atormenta a experiência de pensamento. A linguagem, prestando-se ao uso metafórico, torna-nos capazes de pensar, isto é, de ter trânsito em assuntos não sensíveis, pois permite uma transferência, metapherein, de nossas experiências sensíveis. Não há dois mundos, pois a metáfora os une. ${ }^{40}$

Deixo aqui a teoria da metáfora de Arendt. Eu a trouxe para lembrar o caminho pelo qual ela diz que o pensamento é o domínio sui-generis no qual conseguimos abrir uma lacuna entre o passado e o futuro.

A lacuna entre passado e futuro só se abre na reflexão, cujo tema é aquilo mesmo que está ausente - ou porque já desapareceu ou porque ainda não apareceu. A reflexão traz essas 'regiões' ausentes à presença do espírito; dessa perspectiva, a atividade de pensar pode ser entendida como uma luta contra o próprio tempo. ${ }^{41}$

Vejo que deixo o leitor com mais uma metáfora, essa sobre uma região ausente, que não está sujeita ao tempo. Arendt, lembra, nesse ponto, que, de Parmênides à Hegel, passando pelas "falácias metafísicas" de Platão, os filósofos falam sobre uma região fora do tempo, a partir de onde contemplam a totalidade do mundo. O que sugerem esses sonhos filosóficos? A resposta que ela parece indicar é que se conseguirmos ver melhor os limites e as características dessa região do pensamento que parece saltar fora do tempo teremos dado passos importantes. Ao decidir-se resolutamente por uma teoria da filosofia centrada no valor cognitivo da metáfora, por uma investigação sobre as origens da filosofia ligada à escrita alfabética, por uma caracterização da natureza sui-generis do pensamento conceitual como, por assim, dizer, em um tempo sem tempo, Hannah Arendt abriu caminhos de reflexão que até agora não foram suficientemente honrados. ${ }^{42}$

\section{O MANGUEZAL}

Para encerrar essas reflexões programáticas, quero apresentar uma metáfora criada por Andy Clark, na qual vejo a chance de fundir dois temas que indiquei aqui: a natureza peculiar das dinâmicas cognitivas de segunda ordem, nas quais a filosofia encontra seu lugar, e o tipo peculiar de atemporalidade da vida do espírito, que foi tematizada por Hannah Arendt.

Em "Magic words: how language augments human computation"43, um ensaio dedicado ao tema da linguagem pública como um meio de expansão cognitiva e condição de nossas capacidades metacognitivas, alinhado à ideia que a escrita é um tipo de manipulação do ambiente que transforma radicalmente 40 Arendt, 1992, p. 84.

41 Arendt, 1992, p. 155

42 Peter Sloterdjik, em Morte aparente no pensamento (2014) reconhece e se vale de A Vida do Espírito, na direção que indico aqui.

43 In: Carruthers, 1998. 
nosso espaço cognitivo, Clark traz uma metáfora que ele chama de "efeito manguezal". A descrição começa assim:

Se uma árvore é vista crescendo em uma ilha, qual você acha que veio primeiro? É natural (e geralmente correto) supor que a ilha forneceu o solo fértil no qual uma semente com sorte veio pousar. As florestas de mangue, no entanto, constituem uma exceção reveladora a esta regra geral. O manguezal cresce a partir de uma semente flutuante que se estabelece na água, enraizando em superfícies de barro raso. A muda envia raízes verticais complexas através da superfície da água, culminando no que parece, para todos os efeitos, uma pequena árvore sobre palafitas. O complexo sistema de raízes aéreas, no entanto, logo captura o solo flutuante, as ervas daninhas e os detritos. Depois de um tempo, o acúmulo de matéria aprisionada forma uma pequena ilha. Com o passar do tempo, a ilha cresce cada vez mais. Uma massa crescente dessas ilhas pode eventualmente se fundir, estendendo efetivamente a linha da costa até as árvores! Durante todo esse processo, e apesar de nossas intuições anteriores, é a terra que é progressivamente construída pelas árvores. ${ }^{44}$

Essa descrição da forma mediante a qual os manguezais são formados e crescem é então usada por ele para conduzir uma reflexão sobre a relação entre linguagem e pensamento, entre palavras e pensamentos. Clark quer atacar a visão que diz que a fala está enraizada em pensamentos que preexistem a ela, em benefício de uma visão complementar, aquela que sustenta que certos pensamentos somente são possíveis por causa de certas propriedades das palavras, como se vê, por exemplo, na poesia. Em especial, com a escrita, abre-se um novo espaço cognitivo, no qual podemos então

inspecionar e re-inspecionar as mesmas ideias, chegando a elas de muitos ângulos diferentes e de muitos modos mentais diferentes. Podemos manter as ideias originais firmes para poder julgá-las e experimentar com segurança alterações sutis. Podemos armazená-las de maneiras que nos permitam compará-las e combiná-las com outros complexos de ideias de maneiras que derrotariam rapidamente a imaginação não aumentada. Dessa maneira, e como observado na seção anterior, as propriedades reais do texto físico transformam o espaço de possíveis pensamentos.

É fácil ver, em linhas gerais, como isso pode acontecer. Pois assim que formulamos um pensamento em palavras (ou no papel), ele se torna um objeto para nós e para os outros. Como objeto, é o tipo de coisa sobre a qual podemos pensar. Ao criar o objeto, não precisamos ter pensamentos sobre pensamentos - mas, uma vez lá, a oportunidade existe imediatamente para atendê-lo como um objeto por si só. O processo de formulação linguística cria, assim, a estrutura estável à qual os pensamentos subsequentes se vinculam..$^{45}$

O "efeito manguezal" consiste então nisso, que palavras e sentenças podem funcionar, em muitos casos, como as raízes aéreas dos manguezais, pois a natureza pública da linguagem faz com elas passem a servir como novos pontos de fixação de pensamentos, "capazes de atrair e posicionar matéria intelectual adicional, criando as ilhas do pensamento de segunda ordem tão características da paisagem cognitiva do

44 Carruthers, 1998, p. 176.

45 Carruthers, p. 176-7. 
Homo sapiens." É no contexto da metáfora do "efeito manguezal" que Clark introduz o conceito de "dinâmica cognitiva de segunda ordem", que venho considerando, desde o começo desse texto, como sendo um exemplar da família da metalinguagem e da distinção entre discurso de primeira e segunda ordem. As abordagens externalistas contemporâneas, como as de Clark, expandem de forma criativa o tema, não apenas pela tematização de instrumentos como "sextantes, compassos, mapas e réguas de cálculo", e, acima de tudo, da escrita, mas pelo esforço especulativo de identificar algumas consequências únicas dessas dinâmicas de segunda ordem, como as nossas capacidades de autoavaliação e autocríticas. Essas capacidades não seriam, nessa visão, apenas refletidas ou expandidas pela linguagem, mas sim "diretamente dependentes da linguagem para sua existência". Essas capacidades estão muito longe de nascer em terra firme, no entanto. Elas vivem em um meio frágil, nem na terra, nem na água. Elas se sustentam, de certa forma e em certa parte, umas nas outras, como a gente. ${ }^{46}$ Eu acrescento: nem na água, nem na terra, como também nem no passado, nem no futuro; nem na descrição do que existe, nem na prescrição do inexistente, o lugar da filosofia, esse espaço de atenção a certos conceitos e pensamentos, parece ser sempre maior do que aquele que podemos ocupar, pois se expande, sem que controlemos isso, para regiões novas da experiência humana, e por vezes é menor e mais modesto do que aquele sugerido pelas falácias em moda.

\section{PARA CONCLUIR}

"Eu não sei a quantas ando". Essa, sugere Wittgenstein nas Investigações Filosóficas, pode ser a forma de um problema filosófico. ${ }^{47}$ É possível que a recorrência dos debates sobre a filosofia do ensino de filosofia, em detrimento da discussão sobre o que devemos fazer no currículo escolar seja a expressão disso: não sabemos bem a quantas andamos, estamos meio perdidos, e assim temos que pensar mais. É tentador dizer que estamos ainda um tanto desorganizados, no sentido lispectoriano da expressão, no que diz respeito à presença curricular da filosofia nas escolas. Nosso extravio se manifesta de muitas formas, e a maior delas não é o verbalismo sobre criação de conceitos. As aulas de filosofia falam muito sobre as novas terras, sobre os futuros e os povos que não existem ainda, e pouco sobre a extensão de nossa mão aos demais professores e disciplinas da escola.

O ensino de filosofia que se pretende como resistência, ao isolar-se como disciplina na escola, pende mais para uma recusa da realidade. Centrado nas decisões solitárias de cada professor, baseado em manuais oficiais que se dão ao direito de não incluir capítulos sobre lógica, retórica, argumentação, filosofia da linguagem, girando em torno de falsos dilemas sobre ensinar a filosofia ou o filosofar, com uma baixa interdisciplinaridade, com uma sensibilidade irrefreável diante da primeira página dos jornais, vamos mais aos barrancos do que aos trancos. Estamos completando em 2020 quatorze anos desde a fixação da obrigatoriedade curricular da filosofia. Quanto e como

46 Esse tipo de elaboração sobre a natureza do pensamento reflexivo nos obriga a ler com alguma distância frases como essa sobre a filosofia: "todo ser humano é obra de si mesmo. Todo ser humano pode, em determinada medida, acompanhar e formatar criticamente seu devir. Dessa maneira, todo ser humano pode se tornar aquilo que é na verdade. A isso, podemos chamar de crítica. Ou, simplesmente, de filosofia". Trata-se de um trecho de uma exposição sobre Walter Benjamin e um novo conceito de crítica de arte, de autoria de Wolfram Eilenberger, em Tempo de Mágicos - A Grande Década da Filosofia - 1919-1929. 47 §123: "A philosophical problem has the form: "I don't know my way about". 
conseguimos responder à essa nova situação? Como avaliamos a renovação curricular, pedagógica e didática, que fizemos nesse período?

Para responder a essas perguntas, precisamos de outras, simples e diretas. Quantas licenciaturas, nesses quatorze anos, fizeram revisões curriculares guiadas, ou, ao menos, sensibilizadas pelo universo de referência do ensino médio? Quantos novos manuais de ensino de filosofia foram produzidos para proporcionar uma integração mínima à escola real que temos, com as demais disciplinas que temos, com as dificuldades de aprendizagem que temos? Quais materiais didáticos temos produzido, em resposta aos desastres nas aprendizagens fundamentais da escola? Assistimos, na aula ao lado, os desafios do ensino de Língua Portuguesa, por exemplo. Sabemos bem que essa área é um chão para todas as demais aprendizagens. Mobilizamos nossas capacidades para somar esforços nessa direção? Mostramos o que pode um professor de Filosofia, que utiliza os melhores instrumentos conceituais dela à serviço da apropriação adequada da leitura e da escrita? Ou seguimos dizendo que somente sabemos que nada sabemos? A política passa por cima de nossos calos, nos derruba a cada hora de aula de Língua Portuguesa, mas seguimos procurando-a nas manchetes do jornal do dia, para nela encaixar um dito de Platão ou Deleuze.

Não apenas continuamos usando os mesmos manuais do século passado, como nos demos ao luxo de escrever novos, que passam ao largo da tematização dos instrumentos da reflexão, para entregá-la pronta e just in time na aula. Na prática seguimos formando docentes de filosofia especializados em falar sobre a caverna de Platão e o bife de Matrix. Servimos um farto cardápio de todo tipo de metáforas e analogias, mas não há duas horas de epistemologia da metáfora nos currículos de formação docente. E assim vamos, quase parando. Felizmente, como diz Clarice, existe a trajetória, "e a trajetória não é apenas um modo de ir. A trajetória somos nós mesmos. Em matéria de viver, nunca se pode chegar antes."

\section{REFERÊNCIAS}

Aguilera, Mariela. Pensamientos de Primer Orden. In: Crítica, Revista Hispanoamericana de Filosofía. v. 45, n. 133 (abril 2013): 55-81.

Arendt, Hannah. A Vida do Espírito. Tradução de Antonio Abranches e outros. Rio de Janeiro. Ed. Relume-Dumará, 1992.

Azevedo, Fernando. A Educação entre dois mundos. Problemas, perspectivas e orientações. São Paulo. Edições Melhoramentos, 1958.

Bermudez, José Luis. Thinking Without Words. Oxford University Press, 2003.

Carruters, Peter \& Boucher, Jill, Org. Language and Thought. Interdisciplinary Themes. Cambridge University Press, 1998.

Chauí, Marilena. Convite à Filosofia. São Paulo: Ática, 2003.

Cixous, Hélène. Reading with Clarice Lispector. University of Minnesota Press: Minneapolis, 1990.

Danto, Arthur. "Philosophy and/as Film and/as if Philosophy", October 23 (1982). p. 4-10. 
Deleuze, Gilles \& Guattari, Félix. 0 que é a Filosofia? Tradução de Bento Prado Jr. e Alberto Alonso Muñoz. Rio de Janeiro, Editora 34, 1992.

Eilenberger, Wolfram. Tempo de Mágicos - A Grande Década da Filosofia - 1919-1929. Tradução de Claudia Abeling. Todavia, São Paulo, 2019.

Freire, Paulo. Educação e Atualidade Brasileira. São Paulo. Cortez Editora, 2003.

Hegel. Princípios da Filosofia do Direito. Tradução de Orlando Vitorino. Livraria Martins Fontes, 1976. Jakobson, Roman. Linguística e Comunicação. Tradução de Izidoro Blikstein e José Paulo Paes. São Paulo, 1977.

Kant, Immanuel. Crítica da Faculdade do Juízo. Tradução de Valério Rohden e António Marques. Rio de Janeiro: Forense Universitária, 2012.

Lispector, Clarice. A paixão segundo G. H. Rio de Janeiro: Nova Fronteira, 1986.

Marx, Karl; Engels, Friedrich. A Ideologia Alemã. Tradução de Rubens Enderle e outros. São Paulo, Editora Boitempo, 2007.

Merleau-Ponty, Maurice. Sinais. Tradução de Fernando Gil. Editorial Minotauro, Lisboa, 1962.

Moser, Benjamin. Clarice, uma biografia. Tradução de José Geraldo Couto. São Paulo: Cosac Naify, 2009. Noë, Alva. Strange Tools: Art and Human Nature. Hill and Wang, 2015.

Noë, Alva. Varieties of Presence. Harvard University Press, 2012.

Nunes, Benedito. O Dorso do Tigre. São Paulo: Editora Perspectiva, 1969.

Rocha, Ronai. Ensino de Filosofia e Currículo. Petrópolis. Editora Vozes, 2008.

Sellars, Wilfrid. Science, Perception, Reality. Ridgeview Pub Co, Atascadero - California, 1991.

Sloterdijk, Peter. Morte aparente no pensamento. Tradução de Carlos Leite. Lisboa: Antropos, 2014.

Witgenstein, Ludwig. Philosophical Investigations. Wiley-Blackwell, 2009.

Wittgenstein, Ludwig. The Blue and the Brown Books. New York. Harper Perennial, 1965. 